\title{
Exploring the fabrication and transfer mechanism of metallic nanostructures on carbon nanomembranes via focused electron beam induced processing
}

\author{
Christian Preischl ${ }^{1}$, Linh Hoang Le ${ }^{2}$, Elif Bilgilisoy ${ }^{1}$, Armin Gölzhäuser ${ }^{2}$ \\ and Hubertus Marbach ${ }^{* 1}$
}

\section{Full Research Paper}

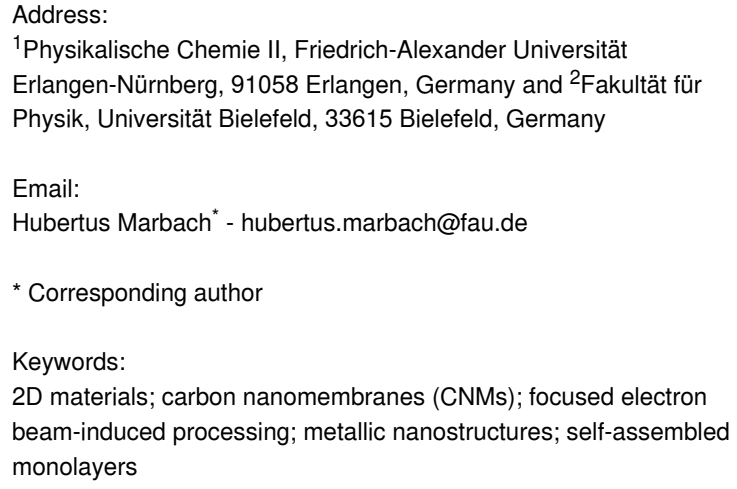

${ }^{1}$ Physikalische Chemie II, Friedrich-Alexander Universität Erlangen-Nürnberg, 91058 Erlangen, Germany and ${ }^{2}$ Fakultät für Physik, Universität Bielefeld, 33615 Bielefeld, Germany

Email:

Hubertus Marbach ${ }^{*}$ - hubertus.marbach@fau.de

* Corresponding author

Keywords:

2D materials; carbon nanomembranes (CNMs); focused electron beam-induced processing; metallic nanostructures; self-assembled monolayers

\author{
Beilstein J. Nanotechnol. 2021, 12, 319-329. \\ https://doi.org/10.3762/bjnano.12.26 \\ Received: 04 December 2020 \\ Accepted: 26 March 2021 \\ Published: 07 April 2021 \\ Associate Editor: P. Leiderer \\ (c) 2021 Preischl et al.; licensee Beilstein-Institut. \\ License and terms: see end of document.
}

\begin{abstract}
Focused electron beam-induced processing is a versatile method for the fabrication of metallic nanostructures with arbitrary shape, in particular, on top of two-dimensional (2D) organic materials, such as self-assembled monolayers (SAMs). Two methods, namely electron beam-induced deposition (EBID) and electron beam-induced surface activation (EBISA) are studied with the precursors $\mathrm{Fe}(\mathrm{CO})_{5}$ and $\mathrm{Co}(\mathrm{CO})_{3} \mathrm{NO}$ on SAMs of $1,1^{\prime}, 4^{\prime}, 1^{\prime \prime}$-terphenyl-4-thiol (TPT). For $\mathrm{Co}(\mathrm{CO})_{3} \mathrm{NO}$ only EBID leads to deposits consisting of cobalt oxide. In the case of $\mathrm{Fe}(\mathrm{CO})_{5}$ EBID and EBISA yield deposits consisting of iron nanocrystals with high purity. Remarkably, the EBISA process exhibits a strong time dependence, which is analyzed in detail for different electron doses. This time dependence is a new phenomenon, which, to the best of our knowledge, was not reported before. The electron-induced cross-linking of the SAM caused by the cleavage of $\mathrm{C}-\mathrm{H}$ bonds and the subsequent formation of new $\mathrm{C}-\mathrm{C}$ bonds between neighboring molecules also seems to play a crucial role in the EBISA process. Previous studies showed that iron nanostructures fabricated on top of a cross-linked SAM on Au/mica can be transferred to solid substrates and grids without any changes, aside from oxidation. Here we demonstrate that iron as well as cobalt oxide structures on top of a cross-linked SAM on Ag/mica do change more significantly. The $\mathrm{Fe}\left(\mathrm{NO}_{3}\right)_{3}$ solution used for etching of the Ag layer also dissolves the cobalt oxide structures and causes dissolution and reduction of the iron structures. These results demonstrate that the fabrication of hybrids of metallic nanostructures onto organic 2D materials is an intrinsically complex procedure. The interactions among the metallic deposits, the substrate for the growth of the SAM, and the associated etching/dissolving agent need to be considered and further studied.
\end{abstract}




\section{Introduction}

Focused electron beam-induced processing (FEBIP) is a powerful maskless "direct-write" approach for the fabrication of arbitrarily shaped nanostructures [1-5]. The most prominent method within the FEBIP family is electron beam-induced deposition (EBID). In EBID, a focused electron beam is used to locally dissociate adsorbed precursor molecules. Thus, a localized deposit of the non-volatile decomposition products forms, while the volatile fragments are pumped off [1-3]. By applying the EBID process it is possible to directly fabricate metallic nanostructures with arbitrary shape and size. Thus, EBID enables the fabrication of well-defined nanostructures [6-8]. Furthermore, the large amount of available precursors allows for the deposition of many different materials [3]. One major challenge in EBID is the undesired co-deposition of carbon and other impurities [4]. The resulting carbonaceous deposits need to undergo further purification steps in order to obtain satisfying results $[4,9]$. However, for certain precursors, EBID yields clean deposits when carried out under ultrahigh vacuum (UHV) conditions. It was shown that in UHV, for some precursors, an autocatalytic growth (AG) process occurs already at room temperature, which leads, upon further precursor dosage, to the dissociation of the precursor molecules on top of the initial EBID deposit. In the case of $\mathrm{Fe}(\mathrm{CO})_{5}$ this $\mathrm{AG}$ process results in the formation of deposits consisting of pure iron [10]. A second method from the FEBIP family, namely electron beam-induced surface activation (EBISA), also largely exploits the AG process [11]. In EBISA, the surface is, in a first step, irradiated and chemically modified without precursor dosage. In a second "development" step, a well-defined deposit is formed at the chemically activated sites, as the precursor is dosed and dissociates locally. Of course, for EBISA a suitable combination of substrate and precursor is a prerequisite, that is, the substrate must be chemically altered by the electron beam and the precursor molecule must be susceptible to the altered site. Substrates that are known to fulfill the prerequisite are silicon oxide $[10,12]$, rutile $\mathrm{TiO}_{2}(110)$ [13], thin layers of porphyrin molecules $[14,15]$, and surface-anchored metal-organic frameworks (SURMOFs) [16,17]. For oxide surfaces it is known that the activation mechanism is based on reactive oxygen vacancies, which are locally created by electron-stimulated oxygen desorption $[18,19]$. Whereas for organic and metal-organic substrates the activation mechanism is still not fully understood [14-17] So far, EBISA was effective with the precursors $\mathrm{Fe}(\mathrm{CO})_{5}$ and $\mathrm{Co}(\mathrm{CO})_{3} \mathrm{NO}$ in UHV $[12,14-18,20]$ and $\mathrm{Co}_{2}(\mathrm{CO})_{8}$ in high vacuum (HV) [13]. The purity of substantial deposits in EBISA is mainly determined by the AG process of the used precursor. For $\mathrm{Fe}(\mathrm{CO})_{5}$ the formation of high-purity crystalline iron deposits is feasible [10-12]. An advantage compared to EBID is that in EBISA the growth of the deposit relies on the AG process only. Therefore, undesired electron proximity effects caused by secondary or backscattered electrons have minor influence on size and shape of the deposit. Recently, it could be demonstrated that FEBIP can be used to fabricate functional hybrid structures consisting of metallic nanostructures on top of organic 2D materials. The prototype of organic 2D materials used in this approach are ultrathin carbon nanomembranes (CNMs) [21]. CNMs are versatile 2D organic materials with high thermal [22] and mechanical [23] stability that can be produced by electron-induced cross-linking of aromatic self-assembled monolayers (SAMs) [24] and transferred onto arbitrary substrates or grids to obtain free-standing 2D membranes [25]. The specific choice of the self-assembling molecules determines the thickness, porosity, stiffness, and the mechanical/ electrical properties of the resulting CNM [26,27]. The SAMs that are used for the fabrication of CNMs consist of aromatic molecules, which are chemically bound to a Au or Ag surface via either thiol [26] or carboxylic [28,29] anchor groups. Via FEBIP, the SAM can be functionalized with metallic nanostructures and subsequently be transformed into a CNM by electroninduced cross-linking. Afterwards, the resulting hybrid structure can be lifted off from the substrate and transferred onto bulk substrates, such as $\mathrm{SiO}_{2}$, or onto TEM grids in order to obtain a free-standing CNM with a metallic nanostructure on top. It was shown that the membrane is mechanically stable enough during the whole process and that the metallic nanostructures fabricated via EBID and $\mathrm{Fe}(\mathrm{CO})_{5}$ remain unchanged, besides oxidation. This result was achieved by using a SAM consisting of $1,1^{\prime}, 4^{\prime}, 1^{\prime \prime}$-terphenyl-4-thiol (TPT) on a Au substrate [21].

In this work, we want to gain more insight into the underlying processes yielding such hybrid nanostructures by investigating the fabrication and transfer on the example of a SAM of TPT on a silver substrate. Consequently, a different chemical etching process is needed for the lift-off process during the transfer. In the case of gold, an etching solution of $\mathrm{KI} / \mathrm{I}_{2} / \mathrm{H}_{2} \mathrm{O}$ is used. Whereas in this approach, the Ag substrate is dissolved by a solution of $\mathrm{Fe}\left(\mathrm{NO}_{3}\right)_{3}$. It is important to study the effect of the underlying substrate and the associated effect on the resulting transferred hybrid structures as, for example, SAMs with carboxylic anchor groups can be fabricated on $\mathrm{Ag}[28,29]$. In order to fabricate well-defined nanostructures it is also essential to study the different FEBIP techniques on SAMs. Therefore, we investigate EBID and EBISA with the precursors $\mathrm{Fe}(\mathrm{CO})_{5}$ and $\mathrm{Co}(\mathrm{CO})_{3} \mathrm{NO}$ on TPT SAMs bound to a Ag surface.

\section{Results and Discussion}

First, the results of EBID and EBISA experiments and subsequent AG with both precursors on a TPT SAM on 
$\operatorname{Ag}(111) /$ mica sample will be discussed. The schematics of these experiments are depicted in Figure 1. For both methods a SAM consisting of TPT molecules bound via the thiol group onto a $300 \mathrm{~nm}$ thick Ag layer on mica was used (Figure 1a). In EBID, the precursor molecules are dissociated by the impact of the focused electron beam (Figure 1b). Whereas in EBISA, in a first step, the SAM is locally activated by the focused electron beam, indicated by the red area in Figure 1c. The formation of a deposit will only occur when these active sites cause the dissociation of the precursor molecules (Figure 1d). Assuming that the two described methods are effective, an initial well-defined local deposit is formed in both cases (Figure 1e). Upon further precursor dosage, the AG process occurs and leads to further agglomeration of material on top of the initial deposit (Figure 1f). If the TPT SAM on $\mathrm{Ag}(111) /$ mica is a suitable substrate for EBISA, both methods should yield well-defined nanostructures (Figure 1g).

Figure 2a and Figure 2d depict two SE micrographs of $2 \times 2 \mu \mathrm{m}^{2}$ deposits fabricated from, respectively, $\mathrm{Fe}(\mathrm{CO})_{5}$ and $\mathrm{CO}(\mathrm{CO})_{3} \mathrm{NO}$ via the EBID $+\mathrm{AG}$ process. In Figure $2 \mathrm{f}$ the corresponding local $\mathrm{AE}$ spectra acquired at the positions indicated with the correspondingly colored stars are plotted. For both precursors selective deposition was observed and no significant unintended co-deposition due to proximity effects [30,31] is visible in the SE micrographs. Local AE spectra of the square fabricated via EBID with $\mathrm{Fe}(\mathrm{CO})_{5}$ reveals that the structure consists of basically pure iron (92 atom \%), with only minor amounts of carbon and oxygen impurities. The square fabricated from $\mathrm{Co}(\mathrm{CO})_{3} \mathrm{NO}$ consists of cobalt (ca. 45 atom \%), oxygen (ca. 45 atom \%), and a small amount ( $<10$ atom \%) of carbon and nitrogen. Obviously EBID with $\mathrm{Co}(\mathrm{CO})_{3} \mathrm{NO}$ works well on a TPT SAM on $\operatorname{Ag}(111) /$ mica. In Figure $2 b$ and Figure 2e two SE micrographs of $2 \times 2 \mu \mathrm{m}^{2}$ deposits, fabricated by EBISA + AG using the same precursors, are depicted. After exposure of $\mathrm{Fe}(\mathrm{CO})_{5}$ a clear deposit is visible in Figure $2 \mathrm{~b}$. The irradiated $2 \times 2 \mu \mathrm{m}^{2}$ area is not completely covered with iron (purity ca. 90 atom \%), as there is no iron at the edges of the square. This process occurs because for EBISA usually a much higher electron dose is necessary to effectively activate the substrate than for EBID. Thus, the edges of the square, which due to the lack of proximity effects are exposed to a lower overall electron dose than the center, are not fully covered. The AG process results in the formation of presumably pure crystalline iron [10,12], as evidenced in the blowup SE image in Figure 2c and the orange spectrum in Figure 2f. In Figure 2e no obvious deposit is visible in the SE micrograph after dosing $\mathrm{Co}(\mathrm{CO})_{3} \mathrm{NO}$. The faint square shape possibly comes from beam damage. The local AE spectrum acquired in the irradiated area exhibits no Co signals but carbon and silver signals, which can be assigned to the substrate. Consequently, EBISA is feasible on a SAM of TPT molecules with $\mathrm{Fe}(\mathrm{CO})_{5}$ but fails on the same substrate with $\mathrm{Co}(\mathrm{CO})_{3} \mathrm{NO}$. This type of chemical selectivity was reported before on other substrates such as SURMOFs $[16,17]$. In contrast, on thin layers of porphyrin molecules EBISA was successful with both precursors $[14,15]$. It is known that electron irradiation of aromatic SAMs causes the cleavage of $\mathrm{C}-\mathrm{H}$ bonds and, thus, the formation of reactive, that is, activated $\mathrm{C}$ species. This is found to be the starting point for the formation of laterally cross-linked CNMs via the formation of $\mathrm{C}-\mathrm{C}$ linked phenyl species [32]. Considering this, one might suspect that the corresponding activated $\mathrm{C}$

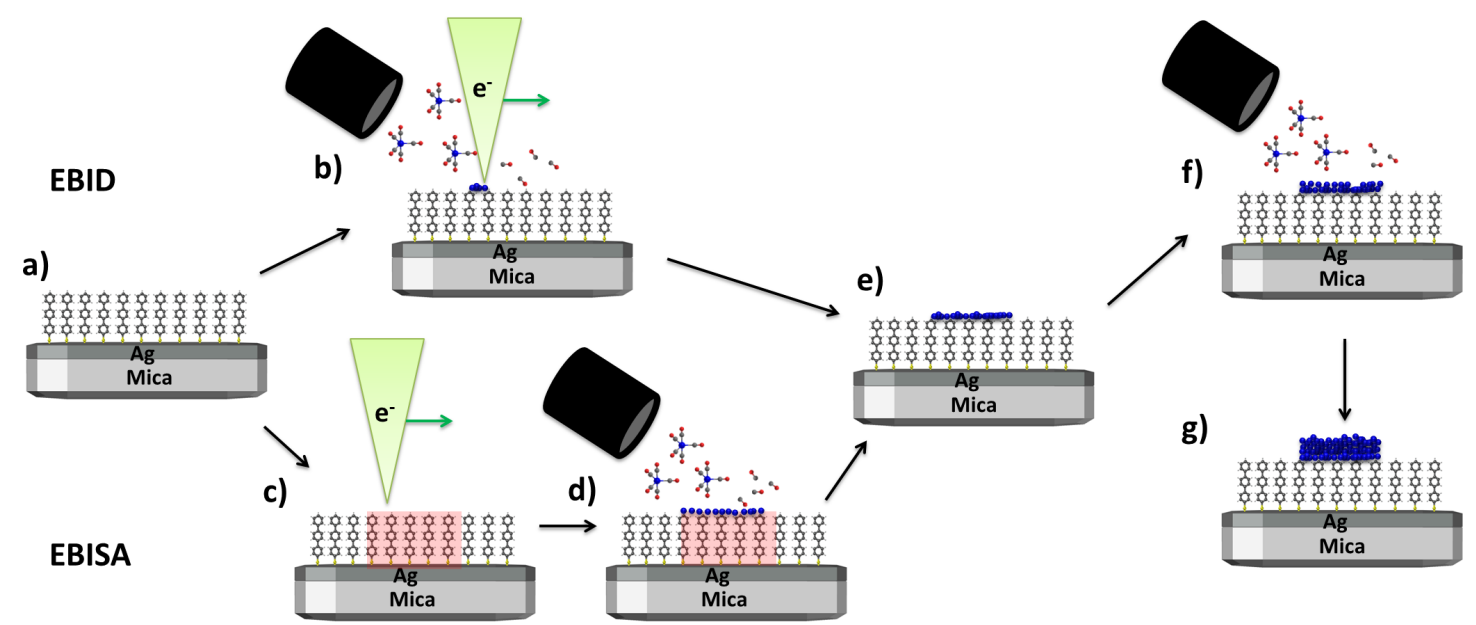

Figure 1: (a) SAM consisting of TPT molecules on a $\mathrm{Ag}(111) /$ mica substrate. (b) EBID process on the SAM Ag substrate. (c) Local activation of the TPT SAM with the focused electron beam within the EBISA process. (d) Precursor dosage after electron irradiation. If EBISA is possible the precursor dissociates locally on the activated sites. (e) Initial deposit that is formed by EBID respectively EBISA. (f) AG process that occurs on top of the initial deposit upon further precursor dosage. (g) Final well-defined nanostructure on top of a TPT on $\mathrm{Ag}(111) / \mathrm{mica}$ sample. 


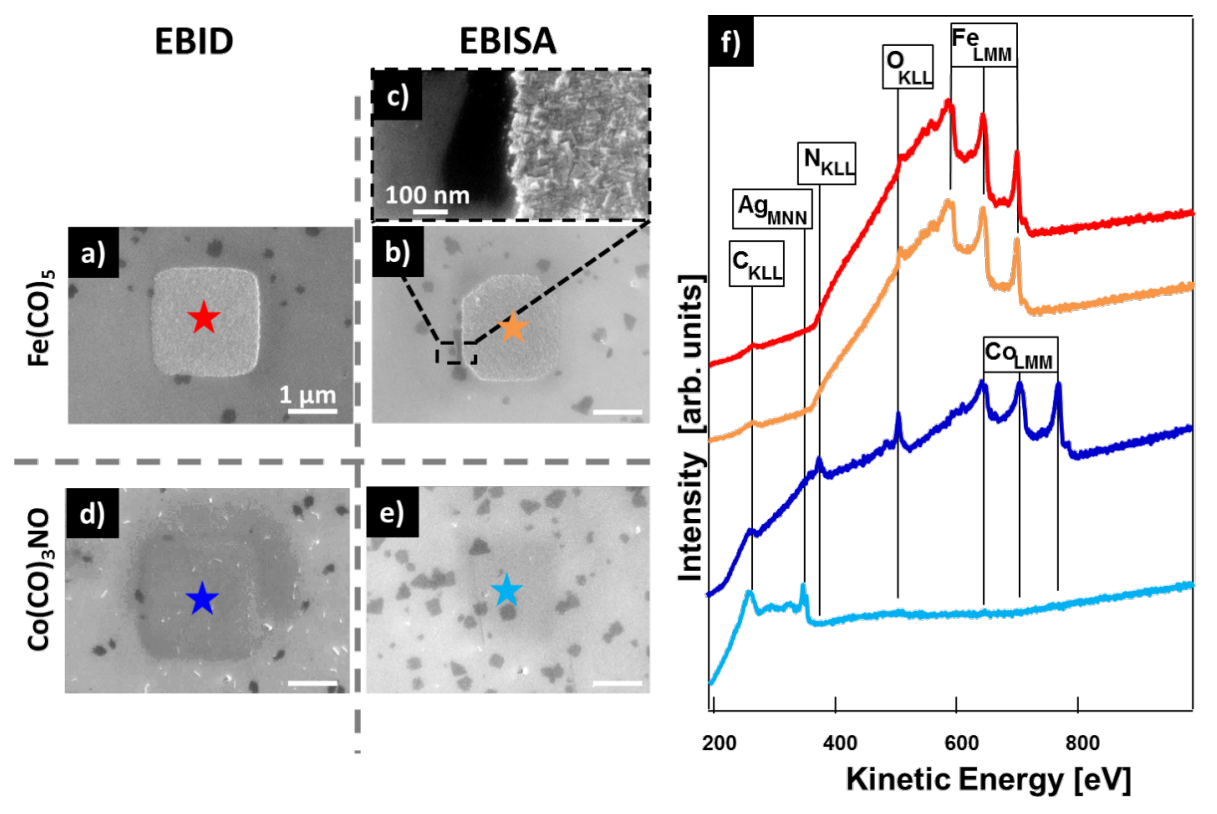

Figure 2: Results of FEBIP experiments followed by autocatalytic growth on a TPT SAM on $\mathrm{Ag}(111) / \mathrm{mica}$. All structures were written with $E_{\text {beam }}=$ $15 \mathrm{kV}$ and $I_{\text {beam }}=400 \mathrm{pA}$. (a) SEM image of a $2 \times 2 \mu \mathrm{m}^{2}$ deposit fabricated via EBID + AG with Fe(CO) $5\left(1.04 \mathrm{C} / \mathrm{cm}^{2}\right.$ and $\left.t_{\mathrm{AG}}=3 \mathrm{~h} 44 \mathrm{~min}\right)$. (b) SEM image of a $2 \times 2 \mu \mathrm{m}^{2}$ deposit fabricated via EBISA + AG with $\mathrm{Fe}(\mathrm{CO})_{5}\left(7.80 \mathrm{C} / \mathrm{cm}^{2}\right.$ and $\left.t_{\mathrm{AG}}=4 \mathrm{~h} 20 \mathrm{~min}\right)$. (c) SEM Blowup image of the structure from (b). (d) SEM image of a $2 \times 2 \mu \mathrm{m}^{2}$ deposit fabricated via EBID $+\mathrm{AG}$ with $\mathrm{Co}(\mathrm{CO})_{3} \mathrm{NO}\left(4.68 \mathrm{C} / \mathrm{cm}^{2}\right.$ and $\left.t_{\mathrm{AG}}=3 \mathrm{~h} 42 \mathrm{~min}\right)$. (e) SEM image of a $2 \times 2 \mu \mathrm{m}^{2}$ deposit fabricated via EBISA + AG with $\mathrm{Co}(\mathrm{CO})_{3} \mathrm{NO}\left(7.80 \mathrm{C} / \mathrm{cm}^{2}\right.$ and $\left.t_{A G}=4 \mathrm{~h} 3 \mathrm{~min}\right)$. (f) Local $\mathrm{AE}$ spectra recorded at the positions indicated with correspondingly colored stars.

species might be also responsible for the dissociation of the $\mathrm{Fe}(\mathrm{CO})_{5}$ precursor. In the following we will present a step-bystep investigation to verify this assumption, which will also lead to a better understanding of the temporal behavior of the activated sites. As a first step, one needs to investigate that it is indeed the SAM, and not the underlying Ag substrate, that is active in the EBISA process. Therefore, EBID and EBISA were also conducted on a clean $\operatorname{Ag}(111) /$ mica sample without the TPT SAM on top. The results are depicted in Figure S1 (Supporting Information File 1) and can be wrapped up as follows. Selective EBID is possible, and EBISA is not working with both of the precursors on the pristine $\operatorname{Ag}(111) /$ mica sample. This evidences that the TPT SAM is crucial for the activation process during EBISA.

In the next step, the EBISA process will be analyzed on a TPT SAM on $\mathrm{Ag}(111) /$ mica that was transformed via electron-induced cross-linking into a CNM beforehand, that is, with a completed cross-linking of the initially electron-activated $\mathrm{C}$ bonds. The results of these experiments are depicted in Figure S2 (Supporting Information File 1). While EBID is still working with $\mathrm{Fe}(\mathrm{CO})_{5}$ on cross-linked TPT SAM (Figure S2a, Supporting Information File 1), in the EBISA process no iron deposit could be located in the irradiated areas (Figure S2b, Supporting Information File 1). It can be concluded that cross-linked TPT cannot be activated anymore by the electron beam such that $\mathrm{Fe}(\mathrm{CO})_{5}$ dissociates at the preirradiated areas. Thus, the predominant $\mathrm{C}-\mathrm{C}$ bonds in the $\mathrm{CNM}$ are either not effectively cleaved during electron exposure or, if they are cleaved, the corresponding sites show no catalytic activity towards the dissociation of $\mathrm{Fe}(\mathrm{CO})_{5}$. Considering that, for the cross-linking, $\mathrm{C}-\mathrm{C}$ bonds are formed from cleaved $\mathrm{C}-\mathrm{H}$ bonds via electron-induced cross-linking [32], the time interval between these processes seems to play a crucial role for the EBISA process. To be more precise, one anticipates a significant time frame in which the cross-linking between electron beam-activated $\mathrm{C}$ atoms occurs based on the latter consideration. To investigate this assumption, we performed experiments in which we varied the waiting time between irradiation of the SAM (Figure 1c) and the following precursor dosage (Figure 1d). In Figure 3 twelve different SE micrographs of $2 \times 2 \mu \mathrm{m}^{2}$ deposits, fabricated from $\mathrm{EBISA}+\mathrm{AG}$ and $\mathrm{Fe}(\mathrm{CO})_{5}$, are depicted. The SE micrographs can be separated in three different electron exposures with doses of 1.01, 3.12, and $6.08 \mathrm{C} / \mathrm{cm}^{2}$. For each exposure four SE micrographs are depicted, which only differ in the waiting time between electron irradiation and precursor dosage. All twelve structures were exposed to $3.0 \times 10^{-7}$ mbar $\mathrm{Fe}(\mathrm{CO})_{5}$ background pressure for $3 \mathrm{~h} 29 \mathrm{~min}$. In addition, local AE spectra were acquired at the positions indicated with the correspondingly colored stars. After a comparably short waiting time of 


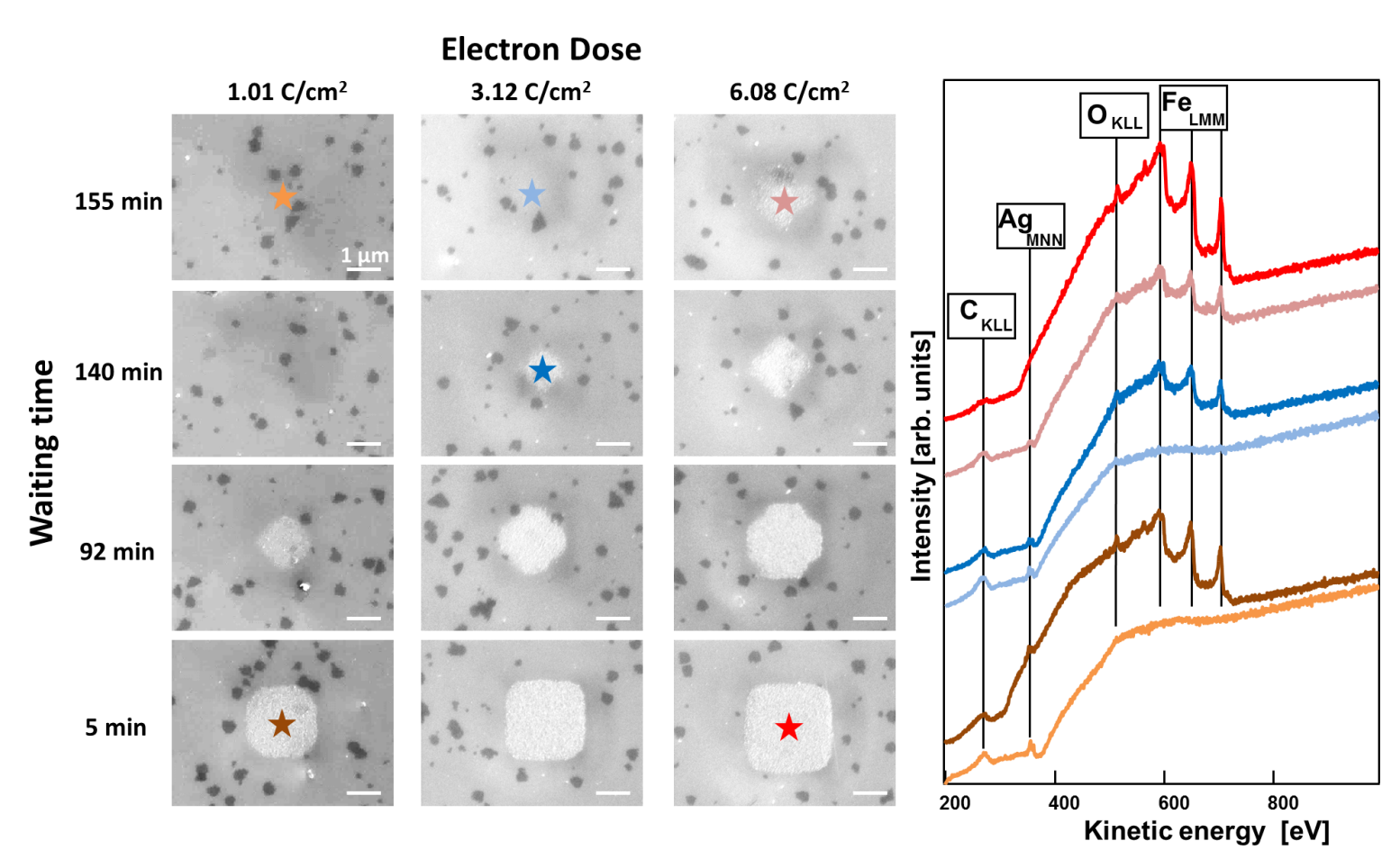

Figure 3: Results of time-dependent EBISA experiments followed by autocatalytic growth on a TPT SAM on Ag(111)/mica. All structures were written with $E_{\text {beam }}=15 \mathrm{kV}, I_{\text {beam }}=3 \mathrm{nA}$, and the same $t_{\mathrm{AG}}=3 \mathrm{~h} 29 \mathrm{~min}$. The SEM images of a $2 \times 2 \mu \mathrm{m}^{2}$ deposit fabricated via EBISA $+A G$ with Fe(CO) 5 can be differentiated regarding electron dose (left column: $1.01 \mathrm{C} / \mathrm{cm}^{2}$; medium column: $3.12 \mathrm{C} / \mathrm{cm}^{2}$; right column: $6.08 \mathrm{C} / \mathrm{cm}^{2}$ ) and waiting time between electron irradiation and precursor dosage. Local AE spectra recorded at the positions indicated with correspondingly colored stars.

5 min, clear and well-defined square deposits are visible in the SEM image for all three applied doses. Local AE spectra of the structures fabricated from 1.01 and $6.08 \mathrm{C} / \mathrm{cm}^{2}$ reveal that the structures consist of iron with very high purity. When the waiting time is increased to $92 \mathrm{~min}$, for all electron doses, the irradiated square areas are apparently not fully covered by deposits. For the highest electron dose of $6.08 \mathrm{C} / \mathrm{cm}^{2}$ just small areas at the edges of the squares are not covered. The area of the uncovered parts increases with decreasing electron dose. At $1.01 \mathrm{C} / \mathrm{cm}^{2}$ the structure rather has the shape of a rhomb than that of a square. After further increasing the waiting time to $140 \mathrm{~min}$, no iron deposit is visible for a dose of $1.01 \mathrm{C} / \mathrm{cm}^{2}$. At $3.12 \mathrm{C} / \mathrm{cm}^{2}$ a small amount of iron is deposited, whereas the covered area is further decreasing compared to $92 \mathrm{~min}$ waiting time. The same is true for the structure fabricated with $6.08 \mathrm{C} / \mathrm{cm}^{2}$. When the waiting time is increased to $155 \mathrm{~min}$ for 1.01 and $3.12 \mathrm{C} / \mathrm{cm}^{2}$, no iron is visible within the irradiated area and no iron is detected in the corresponding local AE spectra. Only at the highest dose of $6.08 \mathrm{C} / \mathrm{cm}^{2}$ a small amount of iron is detected in the local AE spectra. The apparently depositcovered area is further decreasing compared to shorter waiting times. The entire set of the experiment with different values for the waiting time is documented in Supporting Information File 1, Figure S3 (for $1.01 \mathrm{C} / \mathrm{cm}^{2}$ ), Figure S4 (for $3.12 \mathrm{C} / \mathrm{cm}^{2}$ ), and Figure S5 (for $6.08 \mathrm{C} / \mathrm{cm}^{2}$ ). The latter data reveals that the effect apparently directly correlates with the waiting time.

How can this apparent time dependence of the EBISA process, which has been observed for the first time, be explained? Apparently, the amount of activated sites that lead to a dissociation of $\mathrm{Fe}(\mathrm{CO})_{5}$ is decreasing over time. The longer the waiting time between electron irradiation and precursor dosage, the higher is the degree of deactivation of the activated sites. If one assumes that the number of active sites increases with electron dose, the dose-dependent behavior observed in Figure 3 can be derived. It was reported that electron irradiation of aromatic SAMs leads to the cleavage of $\mathrm{C}-\mathrm{H}$ bonds and the formation of cross-linked CNMs via the formation of $\mathrm{C}-\mathrm{C}$ bonds [32]. We thus propose that the cleavage of $\mathrm{C}-\mathrm{H}$ bonds creates reactive sites that are responsible for the dissociation of $\mathrm{Fe}(\mathrm{CO})_{5}$. These active sites might be deactivated over time by reaction with neighboring molecules to form $\mathrm{C}-\mathrm{C}$ bonds, that is, the crosslinking process. If it takes a comparatively long time until all reactive species find a suitable reaction partner, the EBISA deactivation process is anticipated to occur on the same time scale. Another possibility might be that some of the reactive species just do not find a suitable reaction partner due to sterical reasons and are deactivated over time either by residual 
gases in UHV or by an electron quenching effect via the surface or neighboring molecules [32].

EBISA should also work with electrons of rather low energy fabricated by a flood gun instead of the focused electron beam. This macroscopic process is schematically depicted in Figure S6 (Supporting Information File 1). If the precursor gas dosage takes place directly after electron irradiation $(100 \mathrm{eV}$, $120 \mathrm{mC} / \mathrm{cm}^{2}$ ) the whole surface of the cross-linked SAM is afterwards covered with clean iron nanocrystals (Figure S6d,e in Supporting Information File 1). The insulating ultrathin $\mathrm{CNM}$ is covered with a thin layer of conductive ferromagnetic iron crystals. By this process laterally functionalized 2D CNMs can be fabricated.

In a recent study, it was reported that it is possible to fabricate nanostructures on a TPT/Au system and transfer the nanostructures on top of the CNM onto arbitrary substrates. In these experiments the nanostructures retained their shape and did not undergo any changes, aside from oxidation, during the transfer process [21]. In this work, we studied a new system by using TPT SAMs on Ag instead of the analogue SAMs on Au. The main difference caused by changing the substrate is the different wet-chemical etching solution that is necessary for the liftoff process. For etching of the Au layer a solution of $\mathrm{KI} / \mathrm{I}_{2} / \mathrm{H}_{2} \mathrm{O}$ is used, whereas for the dissolution of $\mathrm{Ag}$ a solution of $\mathrm{Fe}\left(\mathrm{NO}_{3}\right)_{3}$ is necessary. The SAM was cross-linked into a CNM by using a flood gun employing $100 \mathrm{eV}$ electrons and an elec- tron dose of $60 \mathrm{mC} / \mathrm{cm}^{2}$ after the EBID structures were fabricated. Before removing the $\mathrm{Ag}$ layer by putting it into a $1 \mathrm{M}$ $\mathrm{Fe}\left(\mathrm{NO}_{3}\right)_{3}$ solution for $24 \mathrm{~h}$, the sample was protected by a $400 \mathrm{~nm}$ thick layer of poly(methyl methacrylate) (PMMA). In a next step, the CNM/EBID/PMMA hybrid structure was transferred onto a $\mathrm{SiO}_{2}$ substrate. Finally, the PMMA was dissolved in acetone. The results for this transfer process with EBID structures fabricated from $\mathrm{Fe}(\mathrm{CO})_{5}$ are depicted in Figure 4. The SE micrograph in Figure 4a depicts a several micrometers large marker structure fabricated via EBID + AG using $\mathrm{Fe}(\mathrm{CO})_{5}$. Through the AG process iron nanocrystals are formed (Figure $4 b$ ). After the transfer onto a bulk $\mathrm{SiO}_{2}$ substrate the same structure could be relocated. However, the appearance in the SEM image of the structure changed (Figure 4c). A bright circular shape is located around the structure. Furthermore, no clear iron nanocrystals are visible anymore in the corresponding blowup image depicted in Figure 4d. Before the transfer, the structure consisted of iron nanocrystals with very high purity ( 87 atom \%) as shown in the AE spectrum in Figure 4e. After the transfer, the structure was oxidized ( 54 atom $\% \mathrm{Fe}$ ) due to exposure to the ambient. The bright circular feature around the structure also consists of iron oxide, whereas no iron is detected on the rest of the surface. Only carbon and oxygen resulting from the $\mathrm{CNM}$ and the underlying $\mathrm{SiO}_{2}$ substrate can be found. Compared to the transfer of a SAM/CNM grown on a layer of $\mathrm{Au}$, where the iron structures remain completely intact aside from oxidation [21], the transfer of a SAM/CNM grown on $\mathrm{Ag}$ induces more significant changes to the deposit. One main

\section{Before transfer}

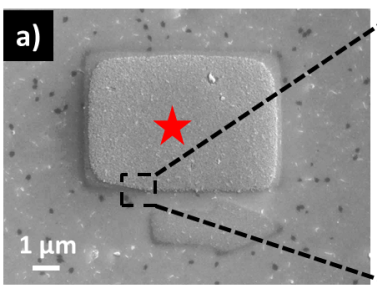

After transfer

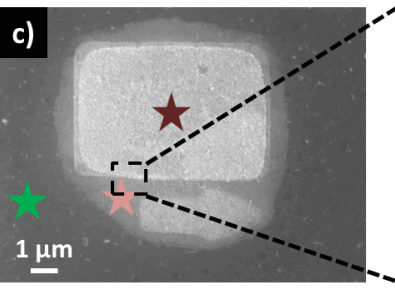

b)
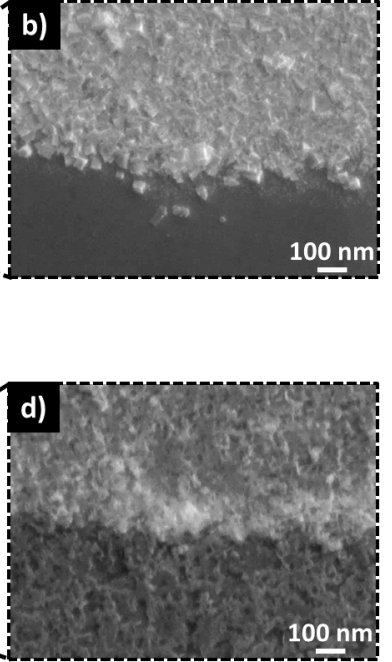

\section{e)}

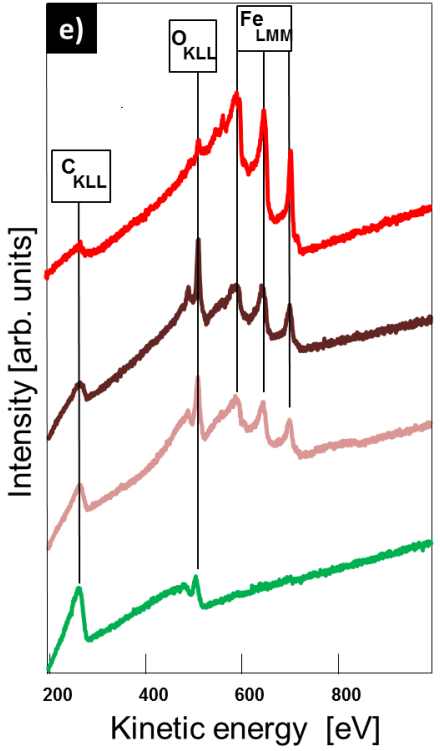

Figure 4: Transfer of a CNM with a Fe structure on top onto a $\mathrm{SiO}_{2}$ sample. (a) SEM image of a Fe structure fabricated with EBID on a TPT SAM on $\mathrm{Ag}(111) / \mathrm{mica}$ (beam parameters $15 \mathrm{kV}, 400 \mathrm{pA}$, electron dose: $0.93 \mathrm{C} / \mathrm{cm}^{2}$, and $\mathrm{AG}$ time: $4 \mathrm{~h} 5 \mathrm{~min}$ ). (b) Blowup image of the structure depicted in (a). (c) SEM image of the Fe structure depicted in (a) after the transfer to bulk $\mathrm{SiO}_{2}$. (d) Blowup image of the structure depicted in (c). (e) Local AES spectra recorded at the positions indicated with the correspondingly colored stars. 
difference of the transfer process is that for the dissolution of the Ag layer the sample is exposed to a $\mathrm{Fe}\left(\mathrm{NO}_{3}\right)_{3}$ solution overnight, whereas the Au layer can be etched away with a $\mathrm{KI} / \mathrm{I}_{2} / \mathrm{H}_{2} \mathrm{O}$ solution within $10 \mathrm{~min}$. Apparently the $\mathrm{Fe}\left(\mathrm{NO}_{3}\right)_{3}$ solution is responsible for the observed effect. It might be possible that the $\mathrm{Fe}\left(\mathrm{NO}_{3}\right)_{3}$ solution is able to diffuse through possible ruptures in the CNM or the PMMA layer. This diffusion process might lead to the dissolution/reduction of the iron structures [33]. The bright circular shape around the structure depicted in Figure 4c can be explained by an incomplete dissolution process. After removing the sample from the $\mathrm{Fe}\left(\mathrm{NO}_{3}\right)_{3}$ solution this type of deformed structure remains.

To gain further insight into the effect of the $\mathrm{Fe}\left(\mathrm{NO}_{3}\right)_{3}$ solution onto the transfer process, AFM measurements were done before and after the transfer. In Figure 5a and Figure 5b, SEM and AFM images, respectively, of five different iron structures are depicted. One larger structure, which acts as a marker structure (the same one as in Figure $4 \mathrm{a}$ ), and four $2 \times 2 \mu \mathrm{m}^{2}$ squares can be seen. The structures are distributed over an area of $50 \times 40 \mu \mathrm{m}^{2}$. The marker structure $\left(7 \times 5 \mu \mathrm{m}^{2}\right)$ is the largest transferred iron structure. In Figure 5c and Figure 5d SEM and AFM images, respectively, of the same five structures after the transfer onto a bulk $\mathrm{SiO}_{2}$ substrate are depicted. The large marker structure decreased in height from $80 \mathrm{~nm}$ before the transfer to $60 \mathrm{~nm}$ after the transfer (Figure 5e). The bright circular feature around the structure exhibits a height of roughly $15 \mathrm{~nm}$ (Figure S7, Supporting Information File 1). For the smaller structures the height decrease was even more pronounced. One example is depicted in Figure 5f. This structure had initially a height of roughly $50 \mathrm{~nm}$, whereas after the transfer the height decreased to ca. $15 \mathrm{~nm}$. This height reduction and the bright circular shape around the structures after the transfer process indicate that the iron structures are slowly dissolved during exposure to the $\mathrm{Fe}\left(\mathrm{NO}_{3}\right)_{3}$ solution.

The same transfer process was also performed with EBID structures fabricated from $\mathrm{Co}(\mathrm{CO})_{3} \mathrm{NO}$. The results are depicted in Figure 6. Figure 6a shows a SEM image of a marker structure fabricated via $\mathrm{EBID}+\mathrm{AG}$ using $\mathrm{Co}(\mathrm{CO})_{3} \mathrm{NO}$. A comparable structure fabricated on the same substrate exhibits a height of $60 \mathrm{~nm}$ (Figure S8, Supporting Information File 1). The resulting deposit consists of small cobalt oxide particles, interpreted on the basis of the corresponding blowup image (Figure 6a) and the local AE spectrum (Figure 6e). Only minor impurities of carbon and nitrogen are detected. In the SEM image recorded after the transfer onto a bulk $\mathrm{SiO}_{2}$ substrate only a faint shape of the original structure is visible (Figure 6c). Furthermore, no cobalt oxide particles are present anymore in the blowup image depicted in Figure 6d. In addition, no cobalt signal was detected in the $\mathrm{AE}$ spectrum recorded in the area where the deposit was located initially. The AE signal is similar to the signal of the pure $\mathrm{CNM}$ on $\mathrm{SiO}_{2}$. It only exhibits carbon and oxygen signals. The cobalt oxide structure has completely vanished after the transfer process. Apparently, the $\mathrm{Fe}\left(\mathrm{NO}_{3}\right)_{3}$ solution dissolves the cobalt oxide structures along with the silver substrate.

In summary, the results from the transfer process of EBID structures on a SAM grown on silver indicate that, in the case of iron, the structures are decreasing in height. Also a bright circu-
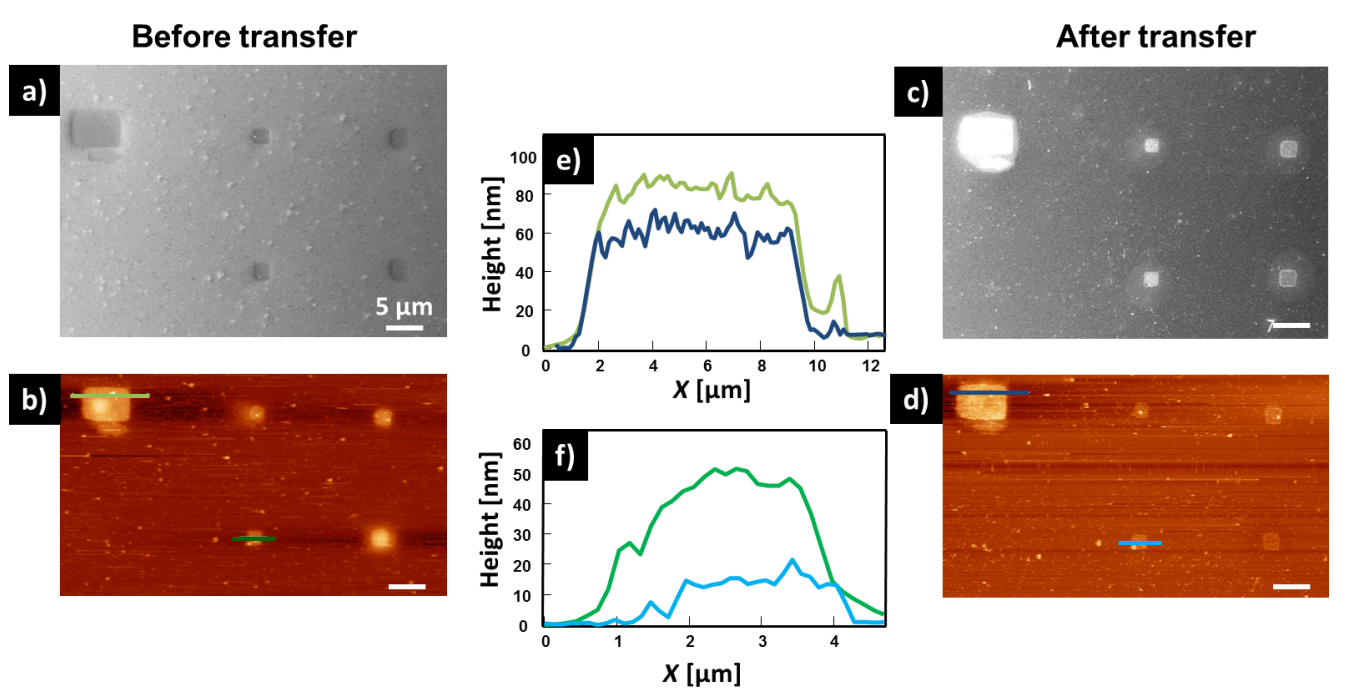

Figure 5: Transfer of a CNM with Fe structures on top onto a $\mathrm{SiO}_{2}$ sample. (a) SEM image of the Fe structures fabricated with EBID on a TPT SAM on $\mathrm{Ag}(111) /$ mica. (b) AFM image of the structures depicted in (a). (c) SEM image of the Fe structures depicted in (a) after the transfer to bulk $\mathrm{SiO}_{2}$. (d) AFM image of the Fe structures after the transfer to bulk $\mathrm{SiO}_{2}$. (e) Height profile of the larger marker structure before and after the transfer. (f) Height profile of a smaller square structure before and after the transfer. 


\section{Before transfer}

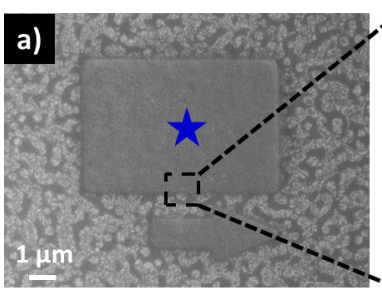

After transfer

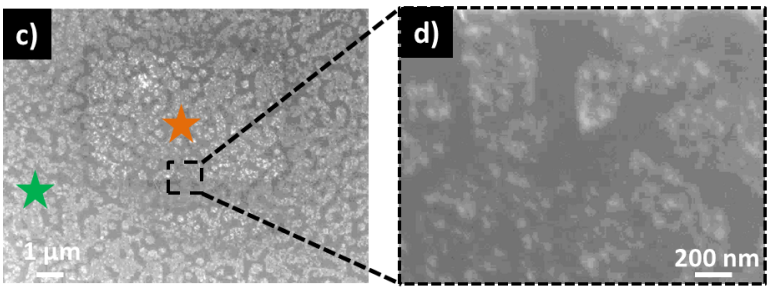

b)

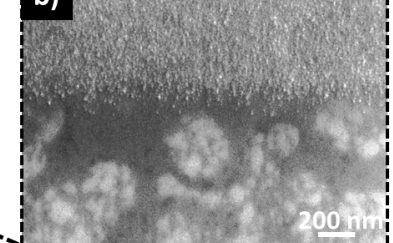

e)

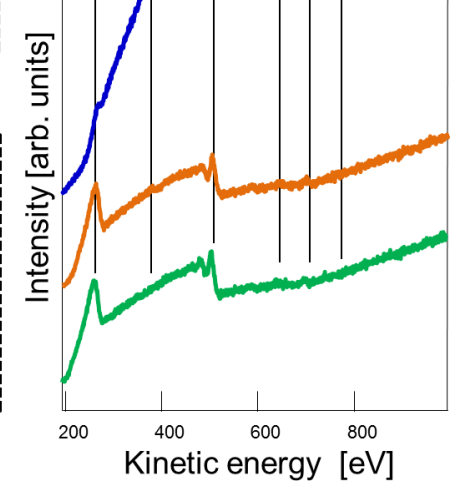

Figure 6: Transfer of a CNM with a cobalt oxide structure on top onto a $\mathrm{SiO}_{2}$ sample. (a) SEM image of a cobalt oxide structure fabricated with EBID on a TPT SAM on Ag(111)/mica (beam parameters $15 \mathrm{kV}, 3 \mathrm{nA}$, electron dose: $0.93 \mathrm{C} / \mathrm{cm}^{2}$, and AG time: $3 \mathrm{~h} 52 \mathrm{~min}$ ). (b) Blowup image of the structure depicted in (a). (c) SEM image of the cobalt oxide structure depicted in (a) after the transfer to bulk $\mathrm{SiO}_{2}$. (d) $\mathrm{Blowup}$ image of the structure depicted in (c). (e) Local AES spectra recorded at the positions indicated with correspondingly colored stars.

lar shape, most probably caused by diffusion and dissolution or reduction [33] in the $\mathrm{Fe}\left(\mathrm{NO}_{3}\right)_{3}$ solution, around the structure is formed. For EBID structures fabricated from $\mathrm{Co}(\mathrm{CO})_{3} \mathrm{NO}$ it is obvious that the $\mathrm{Fe}\left(\mathrm{NO}_{3}\right)_{3}$ solution dissolves the cobalt oxide particles completely. This outcome of the transfer process is schematically depicted in Figure 7. With this we want to emphasize the importance of the underlying substrate and the corresponding chemistry to dissolve the latter in such transfer processes. Maybe other EBID deposits fabricated from Au [34] or Ag [35] precursors are more suitable as they might be more inert towards the $\mathrm{Fe}\left(\mathrm{NO}_{3}\right)_{3}$ solution. Also, a different type of

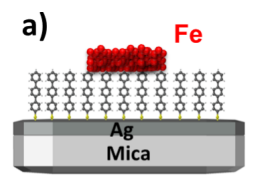

c)

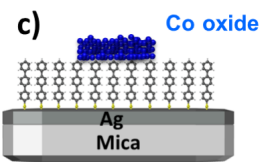

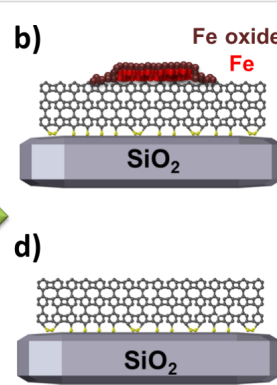
$\mathrm{SiO}_{2}$
Figure 7: Schematic result of the transfer process. (a) Fe structure on top of a TPT SAM on a Ag(111)/mica sample. (b) Fe structure after cross-linking the SAM and transferring the sample onto bulk $\mathrm{SiO}_{2}$. The height decreases, and the structure is oxidized. (c) Cobalt oxide structure on top of TPT on a $\mathrm{Ag}(111) /$ mica sample. (d) After cross-linking the SAM and transferring the sample onto bulk $\mathrm{SiO}_{2}$, the cobalt oxide structure has vanished completely. lift-off mechanism might be more successful regarding the transfer of iron and cobalt oxide structures.

\section{Conclusion}

In conclusion, we investigated two different FEBIP methods, namely EBID and EBISA, on a SAM (TPT) grown on silver. $\mathrm{Fe}(\mathrm{CO})_{5}$ and $\mathrm{Co}(\mathrm{CO})_{3} \mathrm{NO}$ were studied as precursors. We could show that EBID is successful with both precursors, whereas EBISA only works with $\mathrm{Fe}(\mathrm{CO})_{5}$. This type of chemical selectivity was already reported in previous studies on SURMOFs $[16,17]$. For SAMs, we assume that the active species that leads to the dissociation of $\mathrm{Fe}(\mathrm{CO})_{5}$ is formed upon electron-induced cleavage of $\mathrm{C}-\mathrm{H}$ bonds, that is, an activated $\mathrm{C}$ species. Interestingly, we observed a strong time dependence of the EBISA process. The active species seem to get deactivated with time so that no iron will be deposited anymore. This type of deactivation process was not reported before [10,12,14-17]. The mechanism for the time-dependent deactivation process remains somewhat speculative. We narrow it down to two possibilities. First, it might be that the cross-linking is a competing effect, that is, activated carbon atoms are deactivated by cross-linking and, thus, no longer available to decompose subsequently dosed precursor molecules. This would also mean that the crosslinking process is rather slow, that is, it completes in a time frame of an hour or more, depending on the applied electron dose. The second route is proposed to be due to the deactivation via interaction of active sites with residual gas molecules. 
At this point, it should be noted that a mixture of both effects appears to be most likely. However, the quantitative contribution is not known. As it was reported that free-standing hybrid structures consisting of metallic nanostructures on top of CNMs can be fabricated by transferring them from a SAM/CNM grown on $\mathrm{Au}$, we expanded and investigated this process by using a SAM/CNM grown on Ag. In the case of iron structures, diffusion processes caused by the $\mathrm{Fe}\left(\mathrm{NO}_{3}\right)_{3}$ solution, which is used to dissolve the silver layer, lead to a significant height decrease and a change in the appearance of the FEBIP deposits. Structures consisting of cobalt oxide are completely dissolved during the transfer process. Hence, we emphasize that for a successful fabrication of such hybrid structures a suitable combination of substrate for the growth of the SAM, etching solution, and metallic nanostructures needs to be considered. Especially regarding the large amount of possible precursors in FEBIP [4], for each type of metallic nanostructure a suitable transfer mechanism needs to be investigated and the interactions during the transfer process need to be analyzed.

\section{Experimental}

The employed Ag substrates (Georg Albert PVD) consist of a $300 \mathrm{~nm}$ thick layer of $\operatorname{Ag}(111)$ on mica. Prior to SAM preparation, the substrates were soaked for $20 \mathrm{~min}$ and rinsed thoroughly in $N, N$-dimethylformamide (DMF, Sigma-Aldrich, 99.8\%) and then in ethanol (VWR BHD CHEMICALS, 99.9\%). The precursor 1,1',4',1' -terphenyl-4-thiol (TPT) (SigmaAldrich, 97\%) was sublimated before use. Preparation of $\mathrm{SAM} / \mathrm{Ag}$ follows the wet method for the analogous SAMs/Au as described elsewhere [26]. Silver substrates were immersed in a ca. $1 \mathrm{mM}$ TPT solution under argon environment for $24 \mathrm{~h}$ at $70{ }^{\circ} \mathrm{C}$. Then, a repetition of rinsing in DMF and ethanol was applied to the samples in order to remove physically absorbed TPT molecules. The samples were consequently dried by a stream of nitrogen gas and preserved in argon environment until use in FEBID experiments. The FEBIP experiments were performed in a commercial UHV system (Multiscanlab, Omicron Nanotechnology, Germany) with a base pressure of $p<2 \times 10^{-10}$ mbar. The main component of the system is a UHV-compatible electron column (Leo Gemini) for scanning electron microscopy (SEM, nominal resolution better than $3 \mathrm{~nm}$ ) and a local AES using a hemispherical energy analyzer. $\mathrm{Fe}(\mathrm{CO})_{5}$ was purchased from ACROS Organics. $\mathrm{Co}(\mathrm{CO})_{3} \mathrm{NO}$ was purchased from abcr $\mathrm{GmbH} \& \mathrm{Co}$. KG. The quality of the precursor gas was analyzed with a quadrupole mass spectrometer in a dedicated gas analysis chamber (base pressure below $2 \times 10^{-9} \mathrm{mbar}$ ). The precursor gas was dosed through a nozzle with an inner diameter of $3 \mathrm{~mm}$ and a distance of approximately $12 \mathrm{~mm}$ to the sample surface. Based on simulations using GIS Simulator (version 1.5) [36], the local pressure increase on the sample surface was calculated to approximately
$30 \times$. For a fixed background pressure of $3.0 \times 10^{-7} \mathrm{mbar}$, this corresponds to a local pressure at the surface of about $9 \times 10^{-6}$ mbar [37]. All electron exposures for SEM and lithography were performed at a beam energy of $15 \mathrm{kV}$ and probe currents of $400 \mathrm{pA}$ and $3 \mathrm{nA}$, respectively. The lithographic processes were controlled via a self-developed lithography application based on LabView 8.6 (National Instruments) and a high-speed DAC PCIe card (M2i.6021-exp, Spectrum GmbH, Germany). SEM images were acquired with SmartSEM (Zeiss) and are shown with minor contrast and brightness adjustments only. For Auger electron spectroscopy the electron beam of the SEM was used as ionization source at an energy of $15 \mathrm{keV}$ and a beam current of $3.0 \mathrm{nA}$. Spectra were recorded with a hemispherical electron energy analyzer (EA125, Omicron Nanotechnology) and EIS 2.4.24.97 (Omicron Nanotechnology). Data processing was performed with Igor Pro 6.22A (Wavemetrics). The AFM experiments were performed with a JPK NanoWizard 4 by using non-contact mode. Cross-linking of SAMs into CNMs was achieved by using electron flood guns employing $100 \mathrm{eV}$ electrons and an electron dose of $60 \mathrm{mC} / \mathrm{cm}^{2}$. Before starting the transfer process, the cross-linked CNMs were spin coated with a protecting layer of PMMA with an overall thickness of ca. $400 \mathrm{~nm}$. First, a layer of low-molecular-weight PMMA (35 ku), then, a layer of high-molecular-weight PMMA (996 ku) were spin cast each for $1 \mathrm{~min}$ at $4000 \mathrm{rpm}$ and cured on a hot plate at $363 \mathrm{~K}$ for $5 \mathrm{~min}$. The $300 \mathrm{~nm}$ thick silver layer was removed after immersing the sample in a $1 \mathrm{M} \mathrm{Fe}\left(\mathrm{NO}_{3}\right)_{3}$ solution (ACROS Organics). The PMMA/CNM is then transferred into pure water in order to remove iron contamination. In the next step the PMMA/CNM is transferred onto a bulk $\mathrm{SiO}_{2}$ substrate. After drying the sample overnight, the PMMA layer is dissolved by soaking the sample in acetone for $1 \mathrm{~h}$.

\section{Supporting Information}

Supporting Information File 1 contains further information on EBID and EBISA on $\mathrm{Ag}(111)$ /mica surfaces and CNMs, the time dependence of the EBISA process, the "whole-area" EBISA approach, and additional AFM images.

\section{Supporting Information File 1}

Additional experimental data.

[https://www.beilstein-journals.org/bjnano/content/ supplementary/2190-4286-12-26-S1.pdf]

\section{Funding}

This project received funding from the European Union's Horizon 2020 research and innovation programme under the Marie Skłodowska-Curie Grant Agreement No. 722149. The 
Erlangen group acknowledges financial support by the research unit FOR 1878/funCOS.

\section{ORCID ${ }^{\circledR}$ iDs}

Elif Bilgilisoy - https://orcid.org/0000-0002-5295-213X

Armin Gölzhäuser - https://orcid.org/0000-0002-0838-9028

\section{References}

1. Randolph, S. J.; Fowlkes, J. D.; Rack, P. D. Crit. Rev. Solid State Mater. Sci. 2006, 31, 55-89. doi:10.1080/10408430600930438

2. van Dorp, W. F.; Hagen, C. W. J. Appl. Phys. 2008, 104, 081301. doi:10.1063/1.2977587

3. Utke, I.; Hoffmann, P.; Melngailis, J.

J. Vac. Sci. Technol., B: Microelectron. Nanometer Struct.-Process., M eas., Phenom. 2008, 26, 1197. doi:10.1116/1.2955728

4. Botman, A.; Mulders, J. J. L.; Hagen, C. W. Nanotechnology 2009, 20 , 372001. doi:10.1088/0957-4484/20/37/372001

5. Huth, M.; Porrati, F.; Schwalb, C.; Winhold, M.; Sachser, R.; Dukic, M.; Adams, J.; Fantner, G. Beilstein J. Nanotechnol. 2012, 3, 597-619. doi:10.3762/bjnano.3.70

6. Jesse, S.; Borisevich, A. Y.; Fowlkes, J. D.; Lupini, A. R.; Rack, P. D.; Unocic, R. R.; Sumpter, B. G.; Kalinin, S. V.; Belianinov, A.; Ovchinnikova, O. S. ACS Nano 2016, 10, 5600-5618. doi:10.1021/acsnano.6b02489

7. Fowlkes, J. D.; Winkler, R.; Lewis, B. B.; Stanford, M. G.; Plank, H.; Rack, P. D. ACS Nano 2016, 10, 6163-6172. doi:10.1021/acsnano.6b02108

8. Winkler, R.; Fowlkes, J. D.; Rack, P. D.; Plank, H. J. Appl. Phys. 2019, 125, 210901. doi:10.1063/1.5092372

9. Mehendale, S.; Mulders, J. J. L.; Trompenaars, P. H. F. Microelectron. Eng. 2015, 141, 207-210. doi:10.1016/j.mee.2015.03.034

10. Walz, M.-M.; Vollnhals, F.; Schirmer, M.; Steinrück, H.-P.; Marbach, H. Phys. Chem. Chem. Phys. 2011, 13, 17333-17338. doi:10.1039/c1cp20865a

11. Marbach, H. Appl. Phys. A: Mater. Sci. Process. 2014, 117, 987-995. doi:10.1007/s00339-014-8578-x

12. Walz, M.-M.; Schirmer, M.; Vollnhals, F.; Lukasczyk, T.; Steinrück, H.-P.; Marbach, H. Angew. Chem., Int. Ed. 2010, 49, 4669-4673. doi:10.1002/anie.201001308

13. Muthukumar, K.; Jeschke, H. O.; Valentí, R.; Begun, E.; Schwenk, J.; Porrati, F.; Huth, M. Beilstein J. Nanotechnol. 2012, 3, 546-555. doi:10.3762/bjnano.3.63

14. Vollnhals, F.; Wintrich, P.; Walz, M.-M.; Steinrück, H.-P.; Marbach, H. Langmuir 2013, 29, 12290-12297. doi:10.1021/la4028095

15. Drost, M.; Tu, F.; Vollnhals, F.; Szenti, I.; Kiss, J.; Marbach, H. Small Methods 2017, 1, 1700095. doi:10.1002/smtd.201700095

16. Drost, M.; Tu, F.; Berger, L.; Preischl, C.; Zhou, W.; Gliemann, H.; Wöll, C.; Marbach, H. ACS Nano 2018, 12, 3825-3835. doi:10.1021/acsnano.8b01071

17. Ahlenhoff, K.; Preischl, C.; Swiderek, P.; Marbach, H. J. Phys. Chem. C 2018, 122, 26658-26670. doi:10.1021/acs.jpcc.8b06226

18. Vollnhals, F.; Woolcot, T.; Walz, M.-M.; Seiler, S.; Steinrück, H.-P.; Thornton, G.; Marbach, H. J. Phys. Chem. C 2013, 117, 17674-17679. doi:10.1021/jp405640a

19. Lee, J.; Zhang, Z.; Yates, J. T., Jr. Phys. Rev. B 2009, 79, 081408. doi:10.1103/physrevb.79.081408
20. Vollnhals, F.; Drost, M.; Tu, F.; Carrasco, E.; Späth, A.; Fink, R. H.; Steinrück, H.-P.; Marbach, H. Beilstein J. Nanotechnol. 2014, 5 , 1175-1185. doi:10.3762/bjnano.5.129

21. Preischl, C.; Le, L. H.; Bilgilisoy, E.; Vollnhals, F.; Gölzhäuser, A.; Marbach, H. Small 2020, 16, 2003947. doi:10.1002/smll.202003947

22. Turchanin, A.; El-Desawy, M.; Gölzhäuser, A. Appl. Phys. Lett. 2007, 90, 053102. doi:10.1063/1.2437091

23. Zhang, X.; Neumann, C.; Angelova, P.; Beyer, A.; Gölzhäuser, A. Langmuir 2014, 30, 8221-8227. doi:10.1021/la501961d

24. Geyer, W.; Stadler, V.; Eck, W.; Zharnikov, M.; Gölzhäuser, A.; Grunze, M. Appl. Phys. Lett. 1999, 75, 2401-2403. doi:10.1063/1.125027

25. Nottbohm, C. T.; Beyer, A.; Sologubenko, A. S.; Ennen, I.; Hütten, A.; Rösner, H.; Eck, W.; Mayer, J.; Gölzhäuser, A. Ultramicroscopy 2008, 108, 885-892. doi:10.1016/j.ultramic.2008.02.008

26. Angelova, P.; Vieker, H.; Weber, N.-E.; Matei, D.; Reimer, O.; Meier, I.; Kurasch, S.; Biskupek, J.; Lorbach, D.; Wunderlich, K.; Chen, L.; Terfort, A.; Klapper, M.; Müllen, K.; Kaiser, U.; Gölzhäuser, A.; Turchanin, A. ACS Nano 2013, 7, 6489-6497. doi:10.1021/nn402652f

27. Turchanin, A.; Beyer, A.; Nottbohm, C. T.; Zhang, X.; Stosch, R.; Sologubenko, A.; Mayer, J.; Hinze, P.; Weimann, T.; Gölzhäuser, A. Adv. Mater. (Weinheim, Ger.) 2009, 21, 1233-1237. doi:10.1002/adma.200803078

28. Dementyev, P.; Naberezhnyi, D.; Westphal, M.; Buck, M.; Gölzhäuser, A. ChemPhysChem 2020, 21, 1006-1011. doi:10.1002/cphc.202000150

29. Neumann, C.; Szwed, M.; Frey, M.; Tang, Z.; Kozieł, K.; Cyganik, P.; Turchanin, A. ACS Appl. Mater. Interfaces 2019, 11, 31176-31181. doi:10.1021/acsami.9b09603

30. Plank, H.; Smith, D. A.; Haber, T.; Rack, P. D.; Hofer, F. ACS Nano 2012, 6, 286-294. doi:10.1021/nn204237h

31. Walz, M.-M.; Vollnhals, F.; Rietzler, F.; Schirmer, M.; Steinrück, H.-P.; Marbach, H. Appl. Phys. Lett. 2012, 100, 053118. doi:10.1063/1.3681593

32. Turchanin, A.; Käfer, D.; El-Desawy, M.; Wöll, C.; Witte, G.; Gölzhäuser, A. Langmuir 2009, 25, 7342-7352. doi:10.1021/la803538z

33. Groysman, A. Corrosion for everybody; Springer Science \& Business Media, 2009. doi:10.1007/978-90-481-3477-9

34. Shawrav, M. M.; Taus, P.; Wanzenboeck, H. D.; Schinnerl, M.; Stöger-Pollach, M.; Schwarz, S.; Steiger-Thirsfeld, A.; Bertagnolli, E. Sci. Rep. 2016, 6, 34003. doi:10.1038/srep34003

35. Berger, L.; Madajska, K.; Szymanska, I. B.; Höflich, K.; Polyakov, M. N.; Jurczyk, J.; Guerra-Nuñez, C.; Utke, I. Beilstein J. Nanotechnol. 2018, 9, 224-232. doi:10.3762/bjnano.9.24

36. Friedli, V.; Utke, I. J. Phys. D: Appl. Phys. 2009, 42, 125305. doi:10.1088/0022-3727/42/12/125305

37. Schirmer, M.; Walz, M.-M.; Vollnhals, F.; Lukasczyk, T.; Sandmann, A.; Chen, C.; Steinrück, H.-P.; Marbach, H. Nanotechnology 2011, 22, 085301. doi:10.1088/0957-4484/22/8/085301 


\section{License and Terms}

This is an Open Access article under the terms of the Creative Commons Attribution License (https://creativecommons.org/licenses/by/4.0). Please note that the reuse, redistribution and reproduction in particular requires that the author(s) and source are credited and that individual graphics may be subject to special legal provisions.

The license is subject to the Beilstein Journal of Nanotechnology terms and conditions: (https://www.beilstein-journals.org/bjnano/terms)

The definitive version of this article is the electronic one which can be found at:

https://doi.org/10.3762/bjnano.12.26 